\title{
AN UNUSUAL CASE OF INTRA-OCULAR HAEMORRHAGE*
}

\author{
BY \\ D. W. MCLEAN \\ FOLKESTONE
}

THE condition described here appears to be sufficiently unusual to merit recording. I believe it is by no means unique, but I can find no mention of it in books of reference.

Mrs. E. T., age 43 years, presented herself at an out-patient clinic in September, 1945, complaining that the vision of her left eye had been blurred since the previous evening, and it was found that the pupil was half filled by a bead of bright red blood about three millimetres in diameter. Dilatation revealed the presence of a strand of persistent pupillary membrane, arising from the anterior surface of the iris and stretching roughly horizontally across the pupil. The haemorrhage proceeded from this strand, close to the temporal margin of the pupil and extended forwards in front of the margin. There was no visible haemorrhage elsewhere, and no evidence of a haemorrhagic tendency. No history of trauma could be obtained, but as the patient had been playing with a boisterous child immediately before the onset, the occurrence of a minar injury seemed likely.

Under homatropine the haemorrhage was absorbed completely in seven days leaving the vision unimpaired. The membranous strand remained, and slit-lamp investigation revealed a patent blood vessel in which movement of blood was observed.

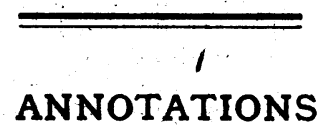

\section{Delay in supply of spectacles}

The delay in obtaining spectacles is to-day causing a considerable amount of anxiety to ophthalmologists and a great deal of inconvenience to patients. It seems curious to many that whereas during the war there was a greater lag between the writing of the prescription and the delivery of the spectacles than existed before the war, this interval is now very much longer, extending usually into a considerable number of weeks and sometimes into an appreciable number of months. The Faculty of Ophthalmologists

* Received for publication, January 28, 1946. 
has recently taken this matter up and it may be of interest to ophthalmologists to know the causes of the hold-up and the prognosis for the future.

Before the war the production of ophthalmic lenses, both massproduced lenses and those individually made, was quite sufficient to meet the demands in this country, and, moreover, to supply a very considerable export trade principally to the Dominions. During the war this production was very considerably hampered by the destruction of a large proportion of optical factories, particularly those in the London area, where, unfortunately, many of them were sited. Despite this, however, largely by the enthusiastic work of the employees and partly by drafting into the industry a large number of women emergency war-workers, the supply of lenses during the war was maintained at a level which satisfied the demands of the fighting Services, of our Allies, and also, to a very considerable extent, of the civilian population. It is to be noted in this connection that in order to aid the industry the fighting Services used only flat lenses. To-day the picture has changed considerably; although the demands of the fighting Services are now practically negligible and the quantity of ophthalmic lenses exported has been limited to token consignments to maintain old-established markets. On the one hand a very large proportion of emergency female labour recruited for the war has ceased working. Unfortunately also the individual output per man has fallen very considerably from the high peak attained and maintained by the enthusiasm of the war, a tendency not limited to the optical trade alone. Despite this, however, owing to the whole-hearted effort and internal co-ordination of the industry, the total output of lenses in this country to-day is considerably higher than it was before the war.

On the other hand, the demand for spectacles has increased enormously. It is estimated that there are half a million more people wearing spectacles to-day than there were in 1939. This is perhaps a general growing tendency as the population is gradually becoming educated (rightly or wrongly) in the advantages of spectacles in "saving sight." To a considerable extent it may also be due to the fact that a large number of men who were, for example, labourers or agricultural workers before the war and had never experienced the need of spectacles in their work, but had very considerable refractive errors, were given glasses by the Army in order to increase their visual efficiency; having discovered their advantages these men now retain their glasses. In addition, many of the population were drafted into precision work in factories or to clerical work and for the first time found the necessity for optical aids. - Again, the cessation of Woolworth's chain-stores as vendors of spectacles has thrown an increased demand of about a million and a half extra glasses a year on the existing optical trade. 
Finally, the acquisition of wealth by the working classes has stimulated many people who before the war were quite happy to wear flat lenses to demand torics, or who used to be content with one pair of spectacles to buy twô. It is interesting that while before the war the sale of flats compared to torics was about $50: 50$, the demand is now something like 25:75 with the result that the facilities for supplying the former are easy, those for making the latter are strained.

Shortly after the cessation of hostilities there was a sudden and enormous demand all over the country for spectacles, due to the reasons already noted, and also to the fact that a large number of people reglected or did not have the opportunity to renew their spectacles during the six war years. This resulted in the industry being swamped at the end of 1945 and the beginning of 1946 and, since the demand has been fully maintained, it has not yet been able to recover itself. It is estimated however, that as new factories gradually become available and as new employees being trained at present become efficient-a tim $\epsilon$-consuming process averaging about eighteen months-the position ought to be fairly satisfactory towards the end of 1947. In the interim despite the efforts of the trade and despite the fullest support of the Ministries concerned, a considerable delay is inevitable. To assist in minimising this delay the Faculty of Ophthalmologists has made certain recommendations which will be found below. They are not, of course, compulsorily applicable but there is no doubt that if they are generally applied not only will the individual patients concerned receive their spectacles sooner, in many cases by some weeks, but the problem as a whole will be to some extent relieved. It is hoped that ophthalmologists generally will study them and comply with them in so far as they can until the position becomes satisfactory.

Looking into the future, however, the next problem will be how far the present swollen demand for spectacles will be still increased when they become a "free" issue in a National Health Service. It may well be that increased manufacturing facilities will be able to meet the demand. We can only hope that they will.

The Faculty's recommendations are as follows:-

1. Except in cases of genuine medical urgency, avoid priority orders.

2. Unless there are good reasons for the contrary, avoid prescribing $1 / 8$ powers, and $\frac{1}{4}$ powers over $4 \mathrm{D}$.

3 . In the lower ranges, covering the "stock powers," prescribe ftat lenses whenever possible, except in the case of bifocals where torics. should be ordered.

4. Avoid ordering tinted lenses wherever possible. When ordered, give as alternative tints either Crookes' or Softlite.

5. Where possible, indicate on the prescription that a variation 
of $\frac{1}{4} \mathrm{D}$. up or down is permissable. It is suggested that this should be done by the sign " \pm 0.25 " on the prescription.

6. Avoid prescribing prisms unless really necessary. All prescriptions including a prism, other than those that can be dispensed by decentration, demand special grinding.

\section{On consulting rooms}

This room is the centre of the ophthalmologists activitics. How ever far his tentacles may spread by way of nursing homes and country journeys the vast majority of his work is done in his consulting room. For eye work a large room, though not essential, is best. We always liked to have a twenty foot range from the test types to the patient, without any arrangement of mirrors to reflect the image of the letters. Up till now most consulting rooms have been makeshift adaptations of some living room in an oldish house. In the future it is possible that consulting rooms will be built specially for the purpose, but it must be owned that our make-shift methods have worked well. It is a convenience if the consulting room be on the same floor à the waiting room; if a half blind patient has to climb the stairs to the first floor there is always a chance of his stumbling and possibly breaking his neck before the ophthalmologist can record his vision. Furniture may be divided into essentials and luxuries. By the essentials we mean a table and chair for the surgeon, a chair for the patient to sit on while he tells his story and comfortable chairs for any relatives or friends who may come with him. If the floor of the room be of any highly polished material it is unwise to rely on small rugs for the covering. These may easily slip and let the patient down and the ophthalmologist be landed in an action for damages for a broken wrist or other bone. On such floors as teak or parquet a carpet is essential. A wash-hand basin is another indispensable piece of furniture. A book case adds to the look of the room and may be filled with either professional or profane literature. In our case complete sets of the Transactions and of this journal should be on the shelves. A few pictures, prints of either Lord Lister or Sir James Paget, or in our own case, Sir William Bowman may be hung on the walls.

Polonius's advice as to raiment is applicable to the furniture; as good as you can afford, "rich but not gaudy." When the writer started in practice he housed for an elder brother a fine copy of a roll-top desk of the Sheraton period, together with an original Bergère chair for his own accommodation. A ribald relative who called on us said that the desk alone was enough to make the fortune of any professional man. It did'nt make our's, for we had to return it to its owner after six months. But the chair adorned our room till a weighty patient, sitting down to write 
a cheque, broke through the cane work of the seat, and after its repair we kept it at home for less ponderous visitors.

The impedimenta of our craft are of course essential and are too well known to need enumeration. Among the luxuries one would include a couch or sofa in case any minor surgery has to be performed on a patient in the supine position. Here, we may state our conviction that it is a mistake to turn the consulting room into an operation theatre. Even chalazia are much better attended to in a nursing home and the charge for the temporary use of the theatre for this small operation does not add much to the patient's expenses.

The room should be furnished for what it is:- a professional man's office. If you have any really valuable furniture, or "rare and curious old masters" you can have these in the room if you like, but our own feeling is in favour of keeping these in the more private parts of the house.

Good blinds and curtains are a necessity unless of course a proper dark room has been constructed in a recess.

A man's hobbies are sometimes reflected in his consulting room. A fisherman may have a stuffed carp in a case on the wall, a biggame enthusiast, a tiger skin on the floor. A mountaineer, a picture of the Matterhorn, or a pair of ice axes placed in saltire over the chimney piece. The gentleman who used the writer's consulting room before he came into residence had been a first class pistol shot, and several cases of pistols were there.

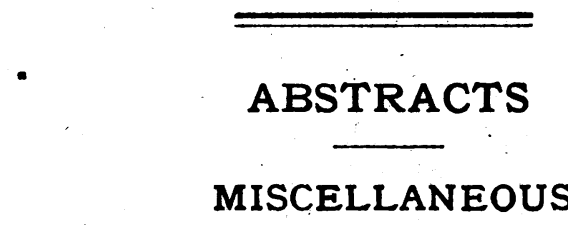

(1) Reese, A. B. (New York).-The iridencleisis operation for glaucoma. Arch. of Ophthal., Vol. XXXIV,- No. 5, p. 360, December, 1945.

(1) The technique evolved by Reese has as its objects:

1. Cutting of the sphincter muscle.

2. Reaching the periphery of the iris with the radial cut.

3. The absence of the root of the iris over the coloboma.

It is carried out as follows, under retro-ocular novocaine and adrenalin. The point of the keratome engages the conjunctiva 10 $\mathrm{mm}$. from the limbus, and drags it down to within $2 \mathrm{~mm}$. of the limbus, where it incises the sclera, being pushed on until at least $\frac{3}{4}$ of the blade is within the anterior chamber. The conjunctival opening is enlarged on each side with scissors, the iris grasped at the 